\title{
Commissioning of the negative ion testbed ELISE
}

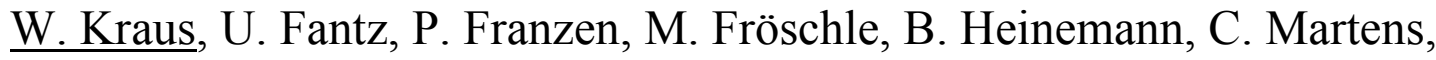 \\ R. Riedl and D. Wünderlich \\ Max Planck Institute for Plasma Physics, EURATOM Association, \\ Boltzmannstr. 2, 85748 Garching, Germany
}

\begin{abstract}
The tests of the large RF driven sources for the ITER neutral beam system will be started on the neutral beam test facility PRIMA in Padua not before 2015. As an important intermediate step a half size ITER source has been designed at Max Planck Institute for Plasma Physics (IPP) and will be operated on the new test facility ELISE (Extraction from a Large Ion Source Experiment) which is presently being commissioned. The target is to generate a negative ion beam of $20 \mathrm{~A}$, accelerated to $60 \mathrm{keV}$. Up to now all components of the test facility are assembled, the power supply, the cooling and the control system have been commissioned and the first plasma will be initiated in September. In preparatory experiments the mutual inductance of two adjacent drivers has been investigated and the coupling of a total RF power of $280 \mathrm{~kW}$ to a similar half size source has been demonstrated.
\end{abstract}

Keywords: $\mathrm{H}^{-}$, Ion Source Development, Neutral Beam Heating, ITER, Radio Frequency Ion Source

PACS: $52.50 . D g$, 52.50.-b, 52.59.-f, 52.70.-m, 52.80.Pi

\section{INTRODUCTION}

In large fusion machines the neutral beam heating systems (NBH) are based on negative Hydrogen ions, because at beam energy of $1 \mathrm{MeV}$, which is required due to the large machine dimensions, only negative ions have sufficiently high neutralization efficiencies. For the NBH of the international fusion reactor ITER RF driven ion sources will be used. This is because of their, in principle, maintenance-free operation that is of particular importance in a radioactive environment. The reliability of RF sources has been proven by fifteen years operation in the positive ion based NBH of the ASDEX Upgrade tokamak (AUG). The negative ions are produced by Caesium enhanced surface conversion of atoms and ions on the plasma grid (first grid of the extraction system). With a small scale prototype the required $\mathrm{H}^{-} / \mathrm{D}^{-}$current densities have been achieved at low source pressure $(<0.3 \mathrm{~Pa})$ in short pulses $(>4 \mathrm{~s})^{1}$. On a long pulse testbed stable $\mathrm{H}^{-} / \mathrm{D}^{-}$beams for up to $3600 \mathrm{~s}$ could be produced ${ }^{2}$. The target value of the accelerated ion current density is $200 \mathrm{~A} / \mathrm{m}^{2}\left(\mathrm{D}^{-}\right)$; therefore, a very large source is needed to achieve the required beam current of $40 \mathrm{~A}$. Thus the ITER source will be $1.8 \times 0.9 \mathrm{~m}^{2}$ and the extraction area will be $0.2 \mathrm{~m}^{2}$. In the IPP prototype source the RF power is inductively coupled into a circular source ("driver") out of which the plasma flows into the main chamber. In order to achieve the ITER source dimensions 
eight of these drivers will be arranged onto the back side of a large expansion volume. Prototypes of the source designed for the NBH of ITER will be tested on the PRIMA (Padua Research on ITER Megavolt Accelerator) ion source test facilities at Consortio $\mathrm{RFX}^{3}$. For a similar source, which will be used in the diagnostic injector of ITER $^{4}$, a third test facility is planned at IPR (Institute for Plasma Research) in Ghandinagar, India.

However, the experiments on these testbeds will not be started before 2015 . Before this there exists no way to develop knowledge of the operation and experience in the extraction of negative ions from RF sources of these dimensions. To bridge this gap two large RF sources with a base area of about half of the size of the ITER source have been designed at IPP, both equipped with four drivers. The RADI source ${ }^{5}$ was operated without beam extraction and was intended to demonstrate the plasma uniformity of a RF source of ITER dimensions and to gain experience in supplying two drivers from a single RF generator, as is planned to occur in the ITER RF circuit.

The goal of the new ELISE testbed is to extract beams of $60 \mathrm{kV} / 20 \mathrm{~A}$ from an advanced four driver source. Beam extraction will be pulsed with a duty cycle of $10 / 180$ s due to limitations of the HV power supply, but the source will be run in steady state. In this way ELISE is an important intermediate part of the road map of European Union's Joint Undertaking for ITER "Fusion for Energy" towards the full size ITER source. The project has been launched in 2009 and the results achieved will support the design and the operation of the full size prototypes of the ITER source.

Because many hardware components like the cryo pumps, vacuum tank, RF and HV power supplies were already available, the assembly of ELISE took much less time than is necessary for the large testbeds in Padua and India.

In this paper the commissioning of the components of the new ELISE testbed is reported. Focus is laid on issues concerning the source operation like RF system, matching and mutual influence of the multi driver system including preparatory experiments with the RADI source.

\section{THE ELISE TESTBED}

An existing spare tank could be used for the vacuum tank, which is identical to that used in the NBH systems of AUG and the Wendelstein 7-X stellerator and by the MANITU testbed. For neutron shielding the entire testbed is encased in a concrete chamber, allowing beam extraction in Deuterium up to 6 hours a year. The source is separated from the tank by a large gate valve (Fig. 1), which can be closed during the regeneration phase of the cryo pumps. In this way the detoriation of the Caesium inside the source by impurities can be avoided; such a separation is so far not foreseen for ITER.

The cryo pumps of the pumping system were previously used for the long pulse testbed MANITU, which was shut down in summer 2011. 


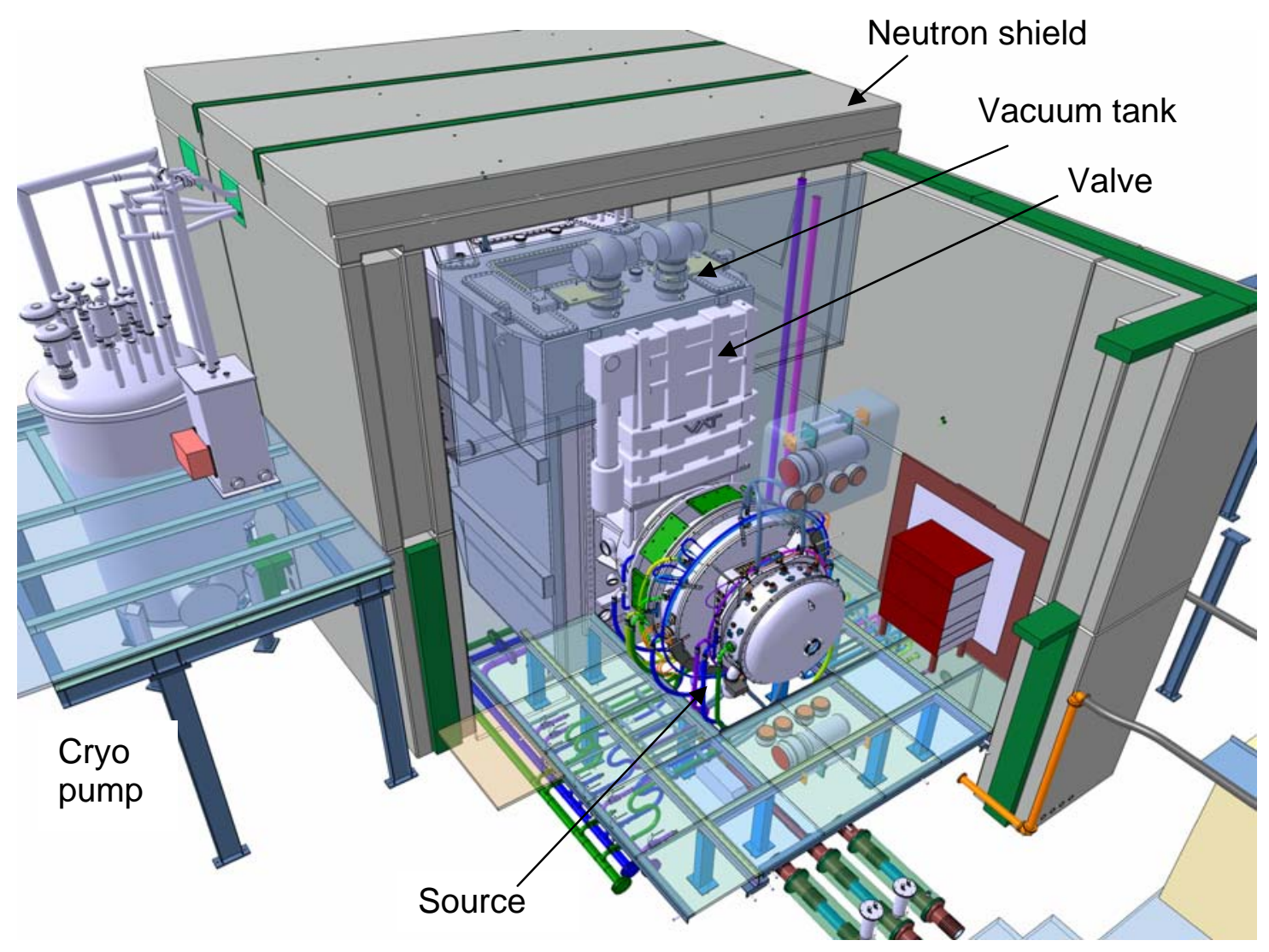

FIGURE 1. The ELISE testbed

\section{EXTRACTION SYSTEM}

The design and manufacture of a new three grid extraction system with a net extraction area of $1000 \mathrm{~cm}^{2}$ has been completed. It consists of 640 apertures of $14 \mathrm{~mm}$ diameter arranged ITER like in 4 groups (Fig. 2). The co-extracted electrons are deflected by small permanent magnets in the second (extraction) grid. The maximum extraction voltage is $12 \mathrm{kV}$. In experiments on smaller testbeds it turned out that for the best source performance the temperature of the plasma grid should be in the range of $150^{\circ}-200^{\circ} \mathrm{C}^{6}$. So the plasma grid is heated by pressurized water of $200^{\circ} \mathrm{C}$. The area of the plasma grid that is not used for beam extraction is covered by the "bias plate", which is an extension of the source walls and provides a Caesium reservoir close to the plasma grid. The current of co-extracted electrons can be controlled by applying a positive potential on plasma grid with respect to the source ${ }^{6}$. The plasma grid and the bias plate are coated with Molybdenum in order to avoid sputtering of the structure material (copper) by plasma ions. The sputter products can detoriate the Cs on the plasma grid and in this way affect the negative ion production ${ }^{2}$. The main insulator is a simple glass ring, with the vacuum forces absorbed by an epoxy cylinder. This is a much simpler and cheaper solution than an alumina insulator of this size. 


\section{ION SOURCE}

Compared to the RADI source, the base area of the ELISE source was enlarged by about $10 \mathrm{~cm}$ in both directions to $1.0 \times 0.87 \mathrm{~m}^{2}$ in order to increase the distance between the edge of the extraction area and the side walls of the source ${ }^{7}$. In this way a more homogeneous plasma density over the extraction area is expected. The side walls and back plate of the source vessel are coated by Nickel, because coating facilities for Molybdenum are not available for parts of this size. The sputtering yield for $\mathrm{Ni}$ is sufficiently low for the inner surfaces of the source, which are exposed to less dense plasma, so that in preliminary tests of $\mathrm{Ni}$ coated inner walls on the long pulse testbed MANITU no degradation of the source performance was observed ${ }^{8}$.

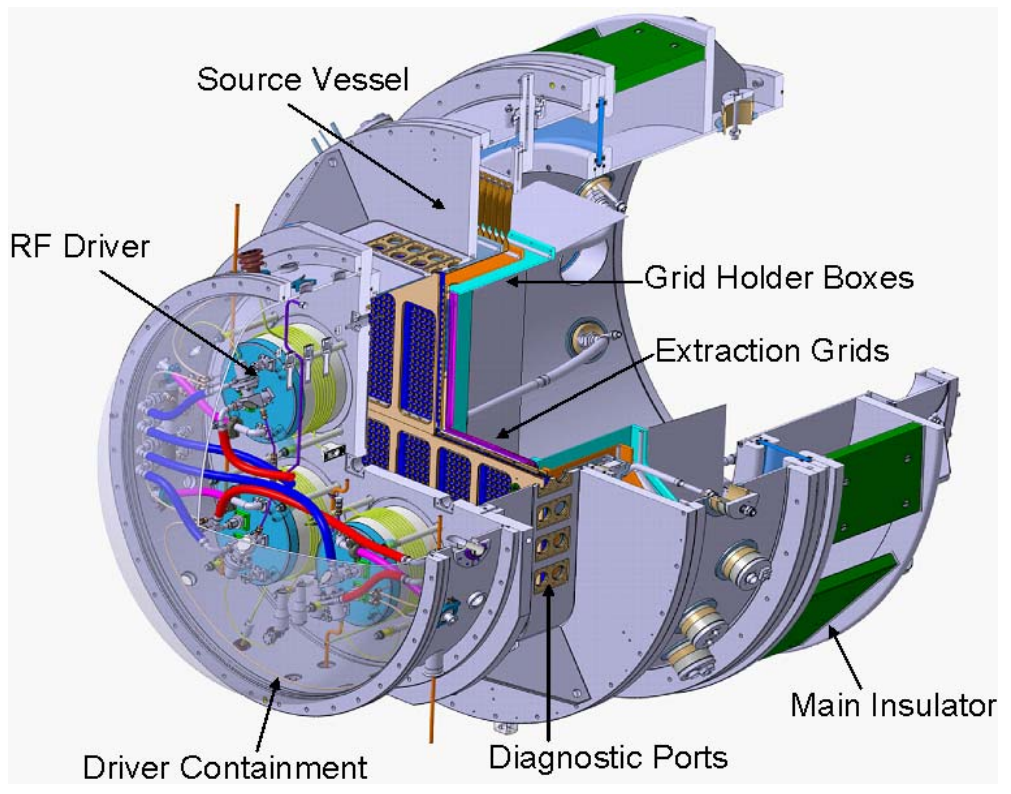

FIGURE 2. Ion source and extraction system of the ELISE testbed

The outer diameter of the four drivers was increased from $26 \mathrm{~cm}$ to $30 \mathrm{~cm}$. The reason was to achieve a more homogenous illumination of the enlarged source and to decrease the power density in the drivers. The latter reduces the effect of neutral depletion that had on the small sources limited the plasma density at high power ${ }^{9}$. A general advantage of multi-driver sources is that the plasma expanding from the drivers overlaps in the middle of the source and so, compared to the small source, each driver supplies a part of the expansion volume with lower wall losses. Therefore, it can be expected that less power is needed to produce the same plasma density in the expansion chamber. This has been already proven by the RADI source, where the power per driver to generate a specific plasma density was significantly lower than on the small source with one driver ${ }^{10}$. At high power the RF voltage at the coils reaches about $20 \mathrm{kV}$ and if the coils are not sufficiently well insulated, RF breakdowns can occur and destroy the coils. On the ELISE drivers the coils are not insulated, but the drivers are in vacuum. Using this kind of insulation the sources for the ASDEXUpgrade NBH have been running reliably for 15 years. 
The Cesium is evaporated by two newly designed dispenser ovens, which are mounted onto side walls with the nozzles directed parallel to the plasma grid ${ }^{11}$.

The width of the large sources exceeds by far the range of permanent magnets, so filter fields can only be generated by a current of up to $8 \mathrm{kA}$ flowing through the plasma grid. In order to reduce the magnetic field in the drivers and to increase the field strength close to the plasma grid the return current is lead back close to the source back plate ${ }^{12}$, leading to a field distribution shown in Fig, 3. An additional advantage of this configuration is the lower field on the extraction side.

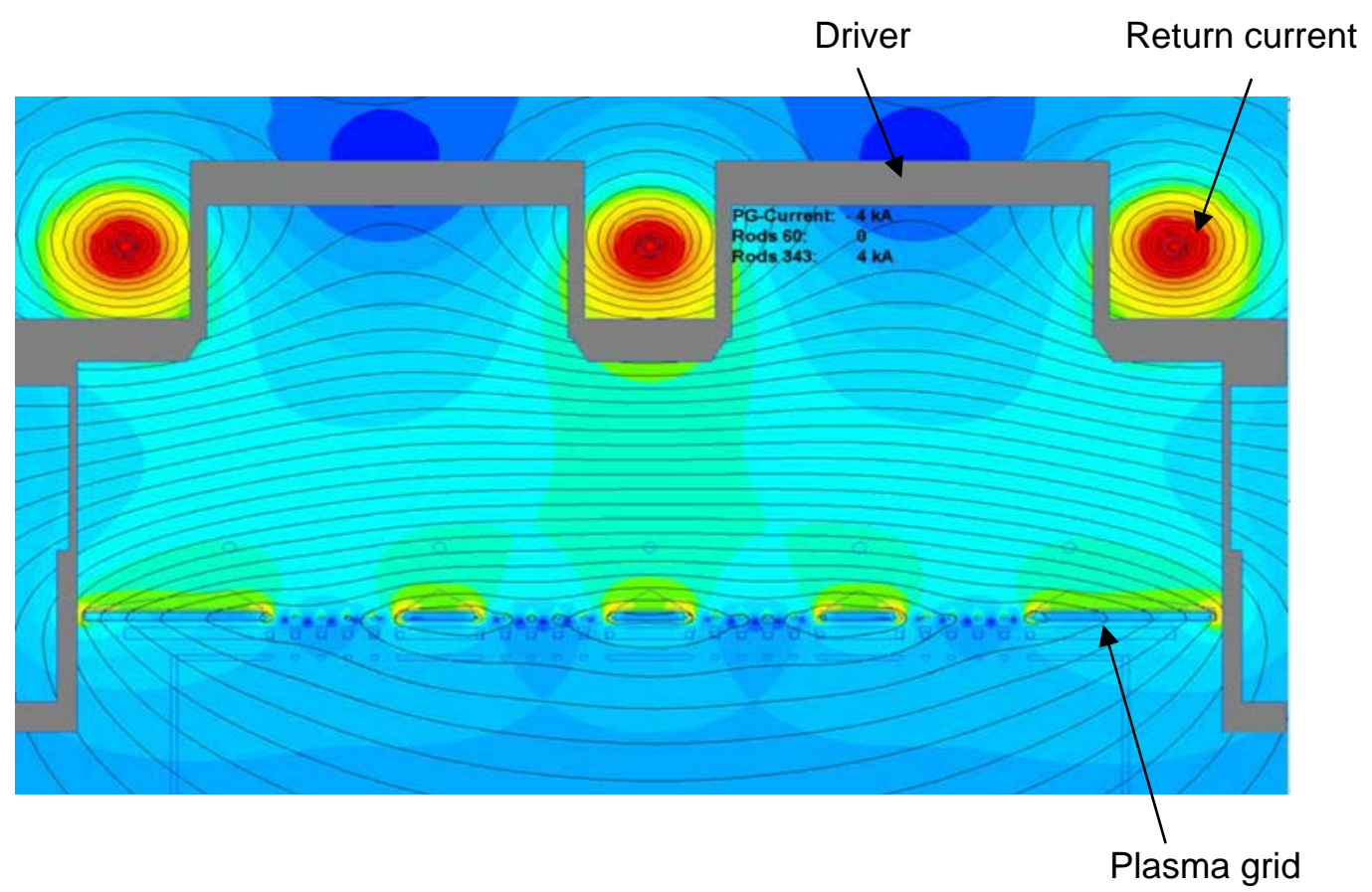

FIGURE 3. Cross section of the filter field generated by a current through the plasma grid

\section{RF POWER SUPPLY}

Two adjacent drivers are connected in series and supplied by a $1 \mathrm{MHz}$ RF generator with a maximum power of $180 \mathrm{~kW}$. The two generators are of the self-excited type and have been upgraded for $\mathrm{cw}$ operation. They were used previously on the RADI testbed. On RADI the drivers of a pair were connected with each other. Consequently on the end of the coil, where they were switched to the matching capacitor, the full RF voltage with respect to ground occurred, leading to problems with RF breakdowns. On ELISE this disadvantage is gone, because the capacitor is now switched between the two coils (see Fig. 4). In this way the capacitor is balanced to ground and only half of the RF voltage occurs at each end of the coils. Such a change of the circuit was only possible, because the connections of the coils are outside the vacuum dome, which, as a further advantage, permits the drivers to be operated separately. In contrast to the ITER design, it is not planned to match by changing the generator frequency, only by the variable capacitor. A second difference to ITER is the use of a transformer, which enables the RF generator to be on ground potential during beam extraction. 


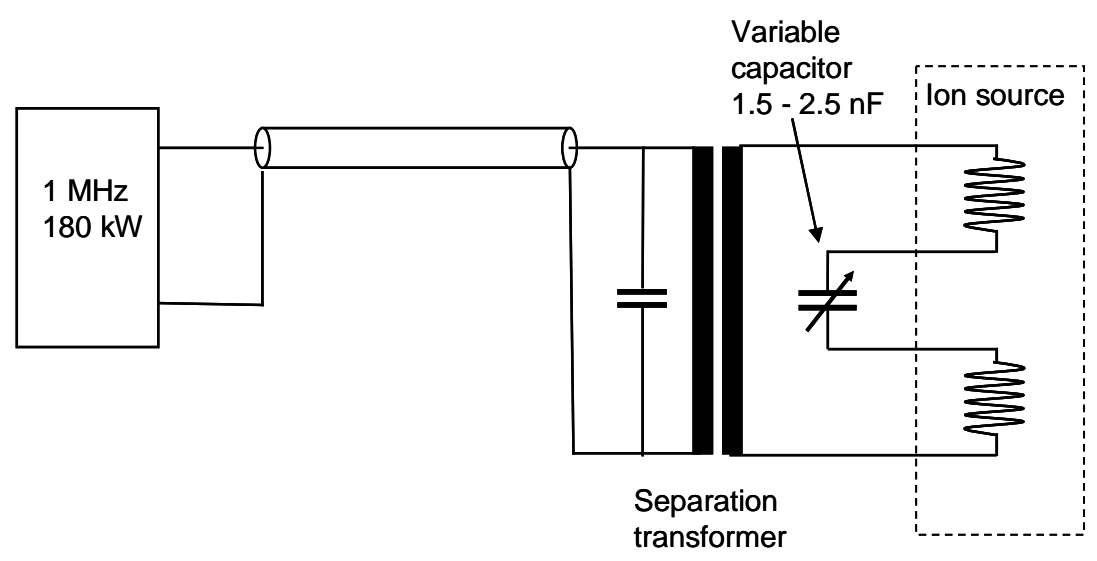

FIGURE 4. Matching circuit for one pair of drivers

\section{EXPERIMENTS WITH THE RADI SOURCE}

Because the drivers are located close together, there was concern that the drivers could affect each other by mutual inductance. But FEM calculations showed that the $\mathrm{RF}$ field of a driver is almost completely shielded by the back plates of the source and the driver and thus only a weak field penetrates into the neighboring driver.

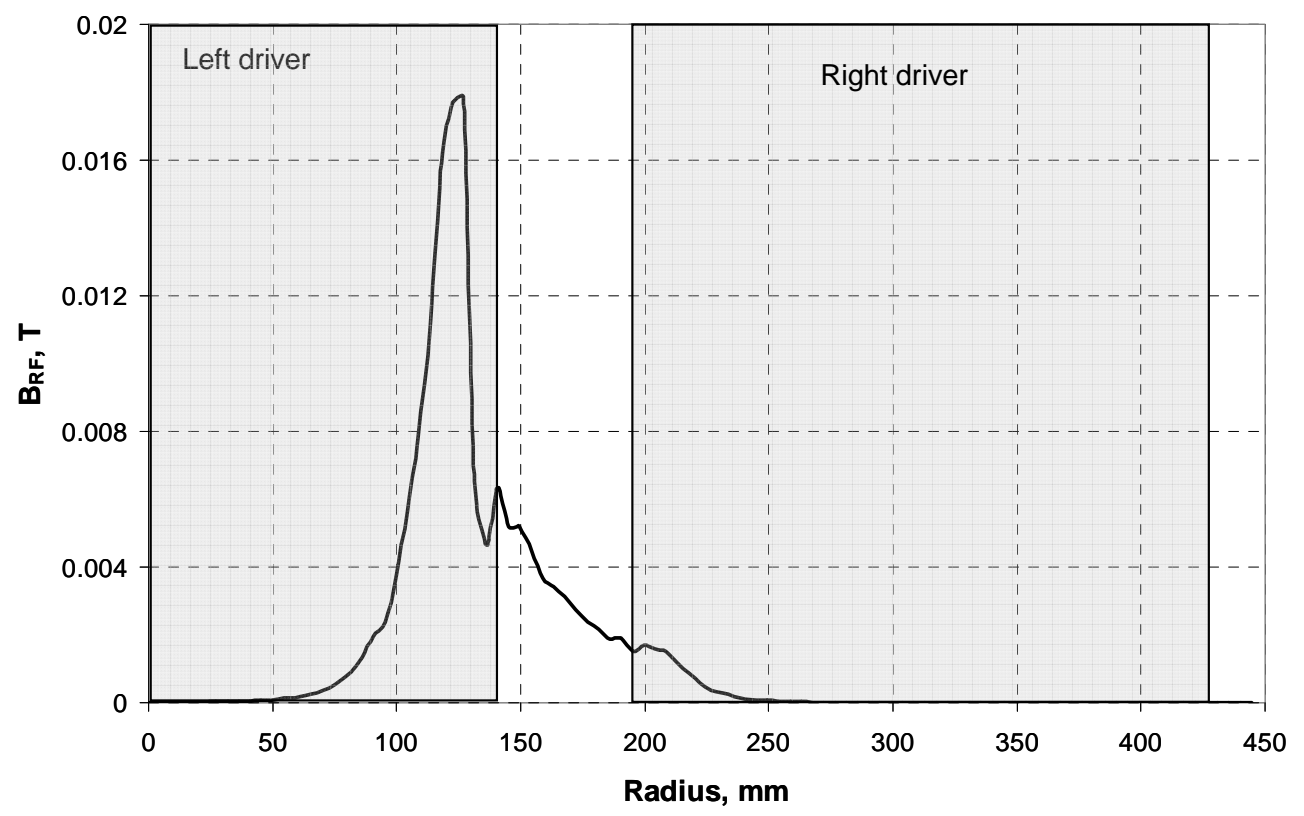

FIGURE 5. Calculated magnetic RF field of the left one of a pair of drivers, the right box indicates the inner wall of the right driver 


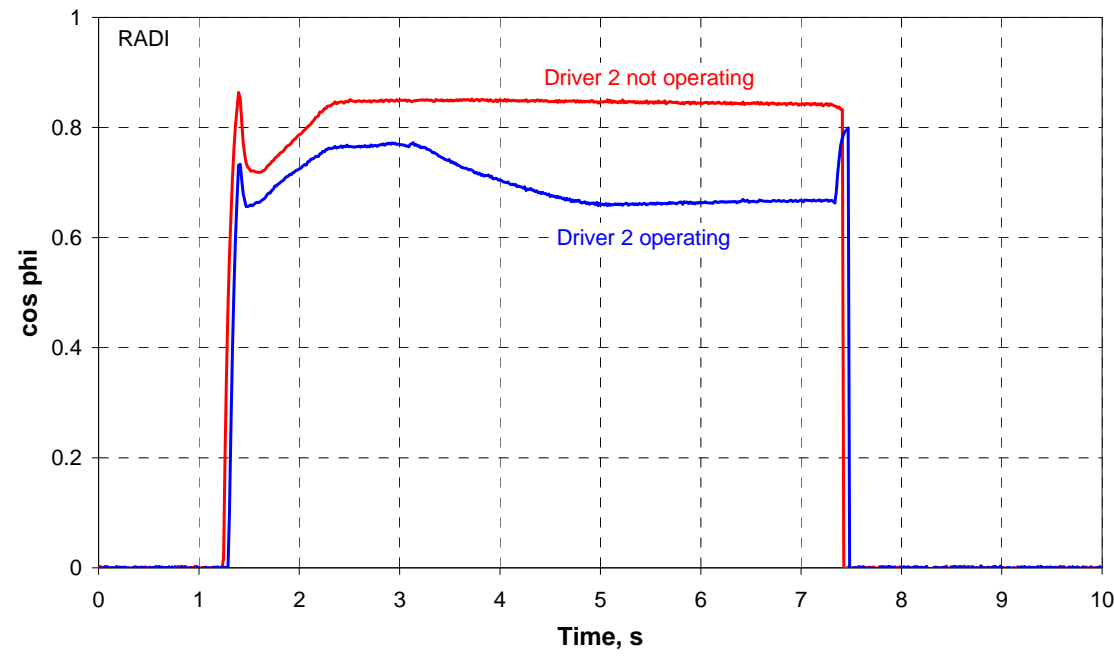

FIGURE 6. Matching of a single RADI driver without shielding with and without operation of the neighbored driver (driver 2)

In matching experiments tests with the RADI source, however, it turned out that, if only one driver of a pair is operated, the matching is different compared to the case when the other driver is also running (see Fig. 6). This effect did not hamper the matching of both drivers in series; a much more serious problem was that from time to time the Faraday shields inside the drivers were damaged by local melting as shown in Fig. 7. This phenomenon occurred even at moderate RF power, but it was almost never observed at the one driver prototype even at high power and in long pulses. Although a comprehensive explanation for the damages has not been found so far, it is assumed that the mutual inductance is the reason for the damage. Therefore, all of the

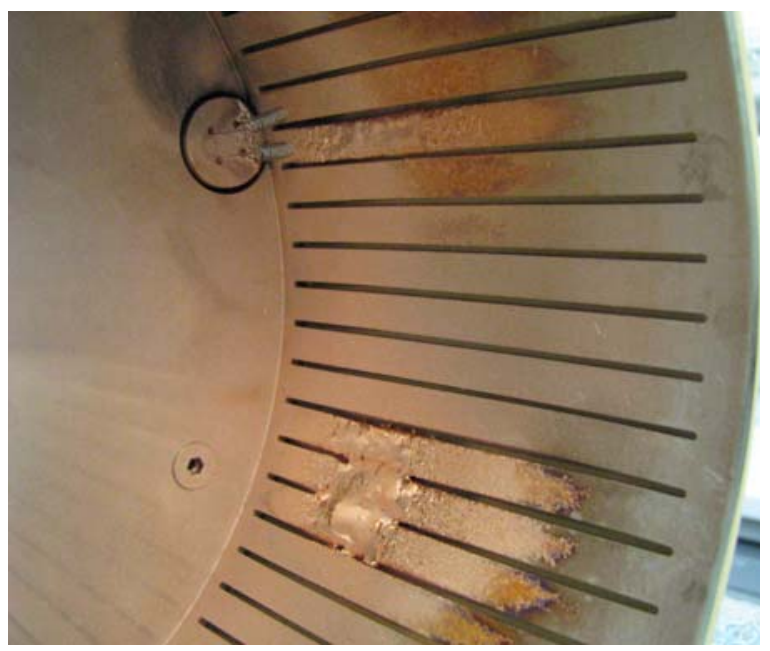

FIGURE 7. Partly melted inner surface of the Faraday shield of a RADI driver without shielding 


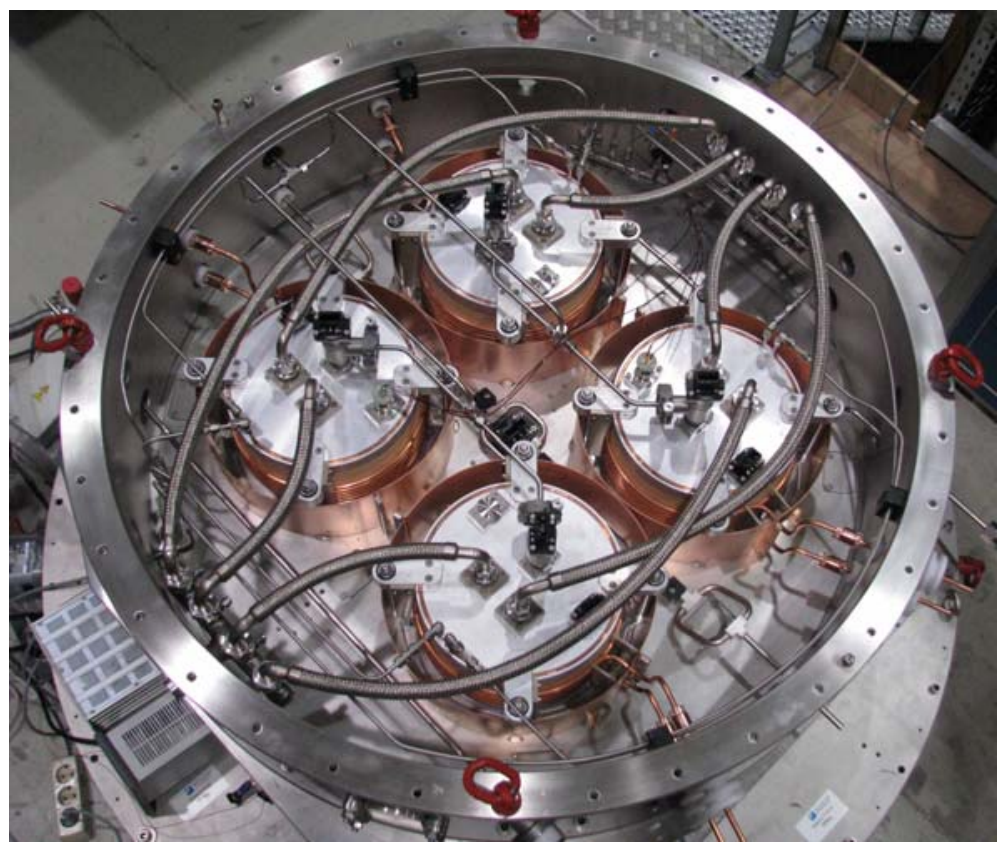

FIGURE 8. ELISE ion source with shielded drivers

RADI drivers were shielded by copper cylinders that terminated the range of the RF fields but did not significantly affect the matching. The power load on these shields from eddy currents is negligible, so that the cooling by thermal contact to the source back plate was sufficient and no additional cooling was needed. After this modification no mutual influence on the matching of single drivers and no severe further damage to the Faraday shields has been observed. So shielding of all drivers was also introduced into the ELISE design (Fig. 8).

In final experiments on the RADI testbed a series of pulses with $2 \times 140 \mathrm{~kW} R F$

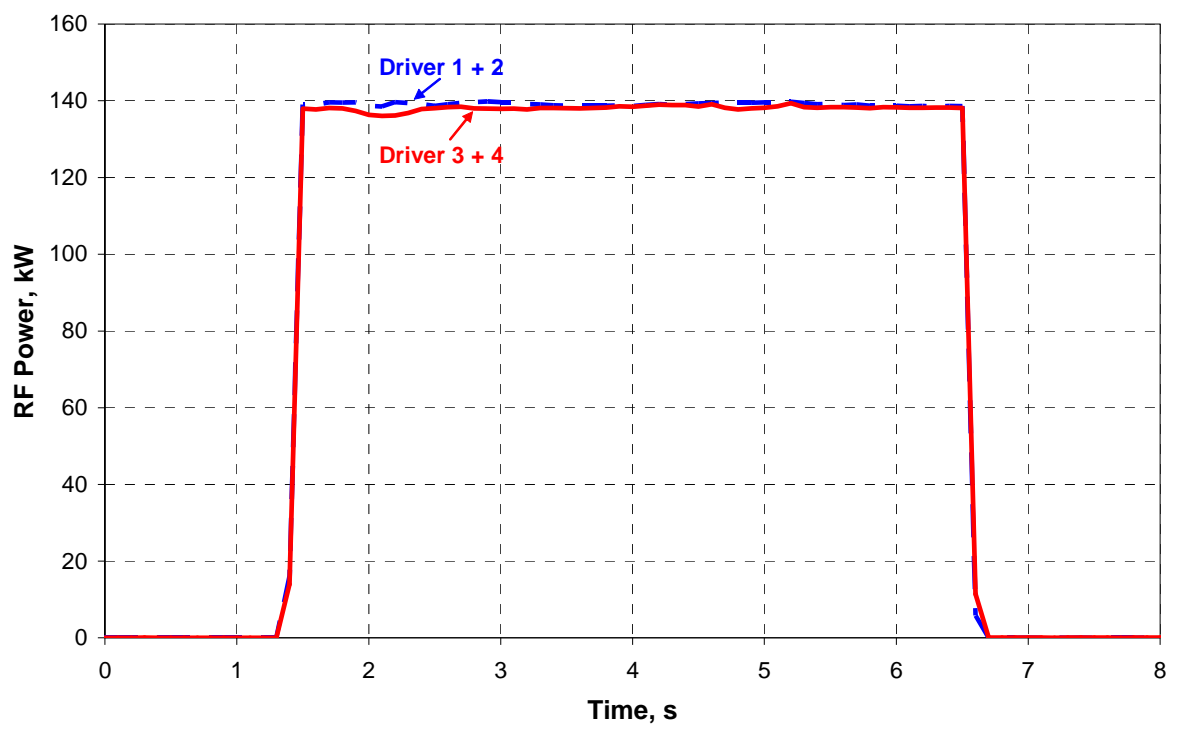

FIGURE 9. 2 x $140 \mathrm{~kW}$ pulse with the RADI source with shielded drivers 
power in $5 \mathrm{~s}$ pulses was performed. One example is shown in Fig. 9. The limiting factor for the maximum power was RF breakdowns in air, which destroyed the coils, when the power was further increased.

\section{STATUS AND FUTURE PLANS}

Technical problems delayed the manufacturing of the source, the coating of the bias plate with Molybdenum, and the Nickel coating of the source. However, the assembly of source has been completed and essential components of the testbed have been tested and commissioned:

- The novel main insulator has been successfully tested with HV up to $120 \mathrm{kV}$.

- Both RF generators have been commissioned on a $50 \Omega$ dummy load in cw operation. After upgrading the power control system the maximum power of $180 \mathrm{~kW}$ has been achieved.

- The vacuum system is operational, except the cryo pumps.

- The control system of the testbed has been tested.

- $\quad$ The cooling system for RF generator, vacuum system and the HV power supply is finished.

After the last minor works are finished, the first plasma operation is now expected in September 2012.

In parallel to the first ELISE operation experiments on the small test facility BATMAN experiments are planned in order to improve the RF power supply and the source concept. The main test is of a semiconductor based amplifier that could replace the self excited oscillator and which offers a higher efficiency and a much more stable frequency. The other experiments are focused on new driver concepts. The goals are to simplify the overall system and reduce the required RF power.

\section{ACKNOWLEDGMENTS}

The work was supported by a contract from Fusion for Energy (F4E-2009-0PE-3201) with an amount of 4 million Euro under the responsibility of Antonio Masiello. The opinions expressed herein are those of the authors only and do not represent the Fusion for Energy's official position.

\section{REFERENCES}

1. P. Franzen, H.D. Falter, U. Fantz, W. Kraus, M. Berger, S. Christ-Koch, M. Fröschle, R. Gutser, B. Heinemann, S. Hilbert, S. Leyer, C. Martens, P. McNeely, R. Riedl, E. Speth and D. Wünderlich, Nucl. Fusion 47(2007)264-270.

2. W. Kraus, H.-D. Falter, U. Fantz, P. Franzen, B. Heinemann, P.McNeely, R. Riedl, E. Speth, Rev. Sci. Instrum. 79, $02 \mathrm{C} 108$ (2008). 
3. D. Marcuzzi, A. Palma, M. Pavei, B. Heinemann, W. Kraus, R. Riedl, Fusion Engineering and De sign 84(2009)1253-1258

4. R. Hemsworth, H. Decamps, J. Graceffa, B. Schunke, M. Tanaka, M. Dremel, A. Tanga, H. P. L. De Esch, F. Geli, J. Milnes, T. Inoue, D. Marcuzzi, P. Sonato, and P. Zaccaria, Nucl. Fusion 49, 045006 (2009).

5. P. Franzen , H. Falter, B. Heinemann, Ch. Martens, U. Fantz, M. Berger, S. Christ-Koch, M. Fröschle, D. Holtum, W. Kraus, S. Leyer, P. McNeely, R. Riedl, R. Süss, S. Obermayer, E. Speth, D. WünderlichFusion Engineering and Design 82 (2007) 407-423

6. W. Kraus, M. Berger, U. Fantz, P. Franzen, M. Fröschle, B. Heinemann, R. Riedl, E. Speth, A. Stäbler, D. Wünderlich, AIP Conf. Proc., 1097, 275(2009).

7. P. Franzen, U. Fantz, W. Kraus, H.D. Falter, B. Heinemann, R. Nocentini, AIP Conf. Proc. Vol $1097,451-460$

8. W. Kraus, U. Fantz, P, Franzen, M. Fröschle, B. Heinemann, R. Riedl, and D. Wünderlich, Rev. Sci. Instrum. 83, 02B104 (2012)

9. P. McNeely, D. Wünderlich, Plasma Sources Sci. Technol. 20(2011) 045005

10.L. Schiesko et al., to be published in Rev. Sci. Instrum. 79, (2012)

11.B. Heinemann, U. Fantz, P. Franzen, M. Froeschle, M. Kircher, W. Kraus, C. Martens, R. Nocentini, R. Riedl, B. Ruf, C. Wimmer, D. Wuenderlich, to be published in Fusion Eng. Des. (2012)

12. M. Fröschle et al., to be published in Fusion Eng. Des. (2012) 